\title{
Structure and biomechanical concept of the equine back
}

\author{
P. René van Weeren \\ Department of Equine Sciences, Faculty of Veterinary Medicine, Utrecht University, The Netherlands
}

\begin{abstract}
Summary
The back is the centrepiece of the equine musculoskeletal system and hence of crucial importance for performance. There is an increase in reported back problems, but the difficult accessibility of the equine back make diagnosis, therapeutic interventions and the evaluation of the effect of any such interventions into somewhat hazardous and very subjective procedures. Therefore, (alleged) ailments of the horse's back are often challenging and unrewarding for the equine practitioner, which makes them at the same time into a relatively easy target for all kinds of alternative therapies with a varying degree of magic by lay people. A thorough and rather detailed knowledge of the structure of the equine back and a profound understanding of its function are prerequisites to deal successfully with these problems. In this paper an overview is given of the anatomy and physiology of the structures that make up the equine back. Emphasis is laid on dynamical and functional aspects, and on the role of the back within the larger framework of the entire musculoskeletal system. The "bow and string" biomechanical concept of the functioning of the back of quadrupedal animals is discussed, including its consequences for the use of the horse. Further, data are given from recent kinematic research on actual spinal movements during the three principal gaits of the horse.
\end{abstract}

Keywords: Anatomy, functional, structur, biomechanic, concept, back

\begin{abstract}
Struktur und biomechanisches Konzept des Pferderückens
Der Rücken ist der zentrale Teil des Muskelskelettsystems des Pferdes und deshalb äußerst wichtig für die athletische Leistung. Die Diagnose "Rückenbeschwerde" wird jetz† viel öfter gemacht wie früher, aber es ist nicht recht deutlich ob dies eine wirkliche Zunahme der Fälle betrifft oder die Wiedergabe ist eines besseren Bewußtseins dieser Probleme. Wegen seiner Größe und Lage ist der Rücken des Pferdes wenig zugänglich und ist es schwierig eine sichere Diagnose zu machen und die Therapie richtig in einer objektiven Weise zu evaluieren. Diese Umstände machen die Behandlung von Rückenbeschwerden schwierig für den Tierarzł und bieten zugleich gute Möglichkeiten für sogenannte alternative Therapien die von oft nicht richtig qualifizierten Leuten mit einer wechselnden Dosis Magie zugepasst werden. Für die richtige Diagnostisierung und Behandlung von Rückenbeschwerden ist ein guter Kenntnis der normalen Struktur und Funktion des Pferderückens unentbehrlich. In diesem Artikel wird einen Übersicht gegeben der wichtigsten Anatomischen Strukturen und fysiologischen Mechanismen des Pferderückens. Der Schwerpunkt liegt bei der sogenannten funktionellen Anatomie: wie kann man das Funktionieren des Pferderückens in biomechanischer Hinsicht darstellen? In diesem Rahmen wird das Konzept des "Bogen und Sehne", wie man das für das Funktionieren des Säugetierrückens entwickelt hat, ausgebreitet besprochen. Zusätzlich werden Daten präsentiert der wichtigsten rezenten Forschungen die man auf dem Gebiet des Funktionieren des Pferderückens gemacht hat.
\end{abstract}

Schlüsselwörter: Anatomie, funktionell, Struktur, Biomechanik, Konzept, Rücken

\section{Introduction}

Interest in equine back problems has increased considerably in recent years. However, they are by no means a new plague to the horse. In 1876 Lupton remarked that back injuries "are among the most common and least understood of equine affections". Back problems are still little understood, mainly because of our limitations in the correct diagnosis of these ailments and in the correct interpretation of the abnormalities that are found.

The overall vagueness and uncertainties surrounding back problems make them into a difficult and often unrewarding challenge for the equine practitioner. At the same time these factors make back problems into an ideal target for the many lay people with varying degree of trustworthiness, who always surround horse owners telling them that their remedies can provide what regular veterinary practice can not.

To better understand the disorders of the equine back it is imperative to have a profound knowledge of the structures that make up this extremely complex entity. It is perhaps even more important to develop a good insight in the functionality and biomechanical behaviour of what is, literally, the bakkbone of the equine musculoskeletal system and hence one of the most vital structures for locomotion. Only when such fundamental knowledge exists it will be possible to evaluate objectively various kinds of (alternative) treatments that are advocated as being beneficial without, in most cases, any scientific evidence. Recently, for instance, a case was reported in which manual manipulative treatment was found to have a significant and lasting influence on spinal motion, although the clinical relevance still remained unclear (Faber et al. 2003)

This paper tries to provide some basic information on equine thoracolumbar structure and function. Emphasis will be laid on functionality rather than on anatomical details and more on dynamic than on static aspects of the thoracolumbar structures, i.e. spinal kinematics and the biomechanical concept of the role of the back in locomotion. 


\section{Structural components of the back and neck}

Bony structures

The spinal column of the horse starts at the occiput of the skull and ends approximately 50 elements later at the end of the tail. Like virtually all mammals, the horse has 7 cervical vertebrae ( $\mathrm{C} 1-\mathrm{C} 7)$. The atlas $(\mathrm{Cl})$ connects the vertebral column with the head and articulates with the epistropheus (C2). These two cervical vertebrae are entirely different in shape compared to the following 5 vertebrae, providing the opportunity for the specific flexion-extension and rotational motions of the head. These motions can relatively easily be checked clinically by manual manipulation after sedation of the horse. After the first two cervical vertebrae, the following vertebrae communicate with each other through the facet joints, each vertebra having a cranial and a caudal set of articular surfaces. In some breeds that are susceptible for the developmental orthopaedic disease osteochondrosis (OC) it has been noted that many $\mathrm{OC}$-lesions can be found in these facet joints. In virtually all cases these lesions are located at the caudal articular surface with not more than some kissingtype lesions at the opposing joint surface (the cranial facet of the next vertebra). The clinical relevance of this finding is not known so far.

The 18 (range 17-19) thoracic vertebrae have a much shorter body than the cervical vertebrae. Whereas the latter have no spinous processes, the spinous processes of the thoracic vertebrae increase rapidly in size with Th2-Th9 forming the basis of the withers. Normally, the tip of Th5 or Th6 forms the highest point of the withers. It is of some importance to note that the tips of Th2-Th7 have separate ossification centres that do not close until at a relatively advanced age (> 10 years). Occasionally, these ossification centres are mistaken for fractures. The spinous processes have a backward inclination from Th1-Th14. The 15th thoracic vertebra has an upright spinous process, and the processes of the remaining thoracic vertebrae and of the lumbar vertebrae have a forward inclination. Although of little clinical relevance, this change in position is of great functional importance and the observation of this peculiarity has helped in forming the current concept how the back functions (see later). The thoracic vertebrae have many articulating surfaces. Apart from facet joints between the consecutive vertebrae, each rib articulates with two adjacent vertebrae.

The average number of lumbar vertebrae is 6 (range 5-7). Their vertebral bodies are longer than those of the thoracic vertebrae, and their spinous processes shorter. The large transverse processes are characteristic. These are positioned very close to each other and the processes of $L 5$ and $L 6$ normally articulate, as do the processes of $L 6$ with the wing of the ileum. The large transversal processes give this part of the spine little mobility. Further, it is not uncommon that also transverse processes located more cranially articulate, or that articulating processes are fused by bony ankylosis. Although this must influence spinal mobility, it will certainly not always result in a clinical problem.

The sacrum is made up of 5 sacral vertebrae that ankylose during the first 4 or 5 years of life, resulting in a completely rigid structure. The sacrum is connected to the ileal wings by the sacro-iliac joint. This joint is formed by ligamentous struc- tures, which leaves little motion possible, however, the joint is not completely rigid in the normal situation. (Sub-) luxations of the sacro-iliac joint are frequent and often result in asymmetries, clinically known as "hunter bumps". Although sometimes very evident, they often do not lead to clinical complaints once the situation has stabilised.

The number of coccygeal vertebrae is very variable (15-21). Unlike in other species such as the cat, the biomechanical role of the tail in horses is limited. In the horse, the tail is not known to influence biomechanical behaviour of the back and/or locomotion in a significant way.

\section{Ligamentous structures}

There are a large variety of ligamentous structures in the equine back. As passive more or less elastic structures they are essential for the biomechanical role of the back (see later). It can be presumed that, as in the limbs, also in the back the role of ligamentous structures and their interfaces with the bony elements of the musculoskeletal system in pathologic conditions has been severely underexposed so far. Progression in this area has long been hampered by the difficulties encountered in visualising these structures. Recent research, however, has shown that many soft tissue abnormalities can be found although the clinical relevance of these has not been firmly established yet in all cases (Denoix 1999). The ligamentous structures that form part of the back can be divided into short and long ligaments. The interarcual ligaments between the vertebral bodies belong to the short ligaments (Fig. 1). They form a kind of elastic interface between adjacent vertebrae and are characterised by the absence of a gel-like nucleus as is common in other species such as dogs and man. Instead, the structure in the horse is fibrous, making classical herniation of the nucleus with ensuing pressure on the spinal cord impossible in this species. The short ligaments also comprise the interspinal ligaments that connect the spinous processes and the intertransverse ligaments between the transverse processes of the lumbar vertebrae (Fig. 1). The interspinal ligaments of the horse are non-

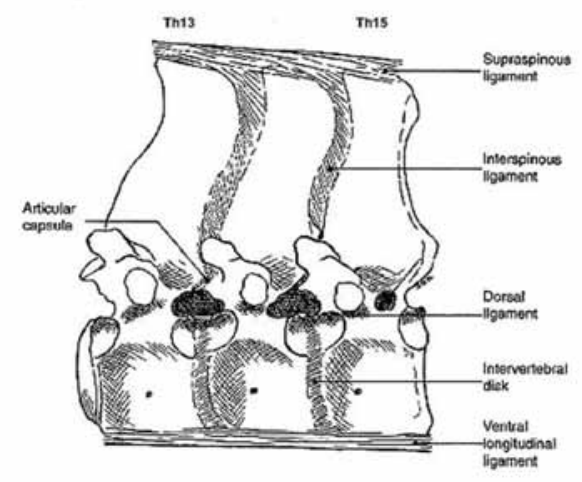

Fig 1 Ligamentous structures between vertebrae. Almost all of these structures have a rather limited elasticity. (Modified from: Denoix J. M. and Pailloux J. P. (2001): Physical Therapy and Massage for the Horse. 2nd ed. London, Manson Publishing.)

Bandstrukturen zwischen den unterschiedenen Wirbeln. Die Mehrzahl dieser Struktutren hat eine sehr begrenzte Elastizität). (Modifiziert aus: Denoix J. M. and Pailloux J. P. (2001): Physical Therapy and Massage for the Horse. 2nd ed. London, Manson Publishing.) 
elastic, except for those in the area of the withers where the spinous processes will make large excursions with respect to each other because of their great length.

The longitudinal dorsal ligament is one of the long ligaments. It runs over the bottom of the spinal canal, i.e. dorsal to the vertebral bodies, from C2 to the sacrum. The ventral longitudinal ligament runs ventral to the vertebral bodies from Th8/9 until the sacrum. Most well known of the long ligaments is the nuchodorsal ligament that consists of a heavy, elastic structure running from the occiput until the first sacral vertebrae. From the withers it is called the supraspinal ligament. Running over the tips of the spinous processes, it is broad until Th 12 and then becomes smaller. A synovial structure between this ligament and the spinous process of Th2, the bursa cucullaris, is often present. Cranial and caudal nuchal bursae may be present too, but are acquired structures. The nuchal ligament is connected to the cervical vertebrae by elastic, laminar structures. The structure as a whole keeps the head in position and is as such an important element in the functional entity that is formed by head, neck and spinal column (see "the back as a functional unit").

Muscles

The great majority of the muscles that attach to bony elements of neck or back run from one part of the axial skeleton to the other, not to parts of the appendicular skeleton. This makes that their primary role is the active, internal stabilisation of the axis of the musculoskeletal system, complimentary to the passive ligamentous structures described above. As a consequence, the system will try to compensate abnormal, asymmetric loading of it (for instance caused by lameness or an unskilful rider) by increased muscle tension. This reaction mechanism of the system explains why, both in man and in the equine species, painful muscle spasms are among the most common and early clinical signs of back problems. It should be realised, however, that such spasms will be in most cases secondary in nature.

There is a deep and a superficial muscle layer. The M. multifidus forms part of the deep layer and has been designated as the longest muscle of the body. It consists, in fact, of a long series of muscle bundles, reinforced with ligamentous strips, that run from the sacrum, the lateral sides of the spinous processes of the lumbar vertebrae and the transverse processes of the thoracic vertebrae to the spinous processes of the vertebrae that are located 2 to 6 positions further craniad. The M. spinalis dorsi et cervicis is another part of the deep layer running from the spinous processes of the lumbar and the last thoracic vertebrae to the spinous processes of the first thoracic and last cervical vertebrae, thus in the same craniodorsal direction as the M. multifidus. The superficial layer is for the largest part formed by the M. longissimus dorsi, in volume one of the largest muscles of the body. The muscle originates from the spinous processes of the lumbar vertebrae and runs to the ribs and first cervical vertebrae. In the lumbar region there is a union with the aponeurosis of the medial gluteal muscle, which is one of the most important retractors of the hind limb and the most important determinant of the driving force of the hindquarters. A smaller muscle is the m. iliocostalis dorsi that runs from the transverse processes of the lumbar vertebrae and the ribs to attach some segments further on the caudal edges of ribs 1-15. The fibre direction of this mus- cle is cranioventral, so opposing the deep layer. It should be noted that almost all epaxial musculature is located dorsal to the spinal column. Only the relatively small psoas muscles run under the spinal column from the pelvis to the ventral side of the lumbar and last thoracic vertebrae. There is no musculature ventral to the cranial part of the thoracic vertebral column.

\section{Innervation}

There are a great many nociceptive receptors located in fascial structures, periosteum and in the numerous ligamentous structures and capsules of articulations. In man it is well known that back pain is as much a pain problem as a back problem, but it is not known whether in horses also other factors than clear-cut pathologies may influence pain perception. No detailed description of the innervation of the structures of the back will be given, but it is important to note that the innervation pattern is segmental in nature. This segmental pattern and the relationship of the various segments system with different organs through the parasympathetic nerve system form the basis of osteopathic practice.

\section{The back as a functional unit}

The question of how the function of the back can best be described dates back to Antiquity. Galenus (AD 130-200) developed the concept of the "vaulted roof" in which the back and the upper part of the rib cage form a roof over the abdominal and thoracic cavities. A collapse of this roof would be prevented by the spinous processes. However, the fact that the spinous processes do not make contact in the normal situation makes this representation improbable. The next concept was developed by Bergmann in 1847 and further elaborated by Zschokke (1892). This concept implies the representation of the back by a bridge that is resting on 4 piers (the limbs) (Fig. 2). The upper ledger represents the supraspinal ligament and withstands tensional forces, the lower one the vertebral bodies, is loaded under compression. The smaller girders between both ledgers represent the spinous processes and the ligaments in between these. Although this concept was generally adhered to until World War II, it contains a basic error in that such a bridge will not be loaded by tension dorsally and by compression ventrally, but just the other way round.

It was the zoologist Sliiper who in 1946, after a meticulous study of the anatomical form of the vertebrae and especially of the inclination of the spinous processes in various species, came up with the model that is still holding today. His so-called bow-and-string concept does not only take into account the vertebral column and the limbs, but also the sternum and musculature of the ventral abdomen. In this concept the vertebral column is a bow that is held under intrinsic tension by the ventral abdominal wall (Fig. 3). Now the bony vertebral column is loaded under compression and the supraspinal ligament under tension (which is the only force it can resist). Various factors determine the ultimate loading of the system (Fig. 4). Contraction of the abdominal musculature, especially of the rectus abdominus muscle, will tense the bow (i.e. flex the back). Indirectly, the same will be achieved indirectly by the retraction of the forelimbs or the protraction of the hind 
limbs. The fusion of the aponeuroses of the gluteus medius muscle and the longissimus dorsi muscle as alluded to earlier may be of importance for the latter mechanism. The string will be tensed (i.e. the back extended) by protraction of the forelimbs and retraction of the hind limbs, but also by the considerable weight of the abdominal organs. The latter effect is



Fig 2 The (erroneous) bridge concept of the vertebral column as depicted by Krüger. Open arrows represent tensile forces, closed arrows compressive forces. (From: Krüger W. (1939) Über die Schwingungen der Wirbelsäule -insbesondere der Wirbelbrücke- des Pferdes während der Bewegung. Berl. Münchn. Tierärtzl. Wschr. 13, 129-133)

Das (falsche) Brückenkonzept der Wirbelsäule wie beschrieben von Krüger. Die offenen Pfeile repräsentieren Zugkräfte, volle Pfeile Druckkräfte. (Aus: Krüger W. (1939): Über die Schwingungen der Wirbelsäule -insbesondere der Wirbelbrücke- des Pferdes während der Bewegung. Berl. Münchn. Tierärtzl. Wschr. 13, 129-133)



Fig 3 "Bow and arrow" concept of the back according to Sliiper. The vertebral column is the bow and the ventral musculature and sternum are the string. The ribs, lateral abdominal musculature, spinous processes and ligamentous connections are additional elements. (From: Sliiper E. J. (1946): Comparative biologic-anatomical investigations on the vertebral column and spinal musculature of mammals. Proc. K. Ned. Acad. Wetensch. 42, 1-128.)

"Bogen und Sehne" Konzept des Rückens nach Slijper. Die Wirbelsäule ist der Bogen, die Bauchmuskulatur und das Brustbein sind die Sehne. Die Rippen, seitliche Muskulatur, die Dornfortsätze und die verbindenden Bänder sind weitere Teile. (Aus: Slijper E. J. (1946): Comparative biologic-anatomical investigations on the vertebral column and spinal musculature of mammals. Proc. K. Ned. Acad. Wetensch. 42, 1-128.)

nicely illustrated by the appearance of many old brood mares with their often very hollow backs. Although in the equestrian circuit many still advocate the contrary, contraction of the epaxial musculature will have an extending effect on the back as well, that is make the back more hollow. Given the fact that the vast majority of the epaxial musculature is located dorsal to the thoracolumbar vertebral column, contraction of this musculature will automatically lead to extension of the back. Of special interest in this biomechanical concept how the back functions is the influence of head and neck movement. If the head is lowered, the nuchodorsal ligament will exert traction on the withers and flex the spinal column (Fig. 5a). Vice versa, lifting of the head will extend the back
(Fig. 5b). Understanding of this concept is of great importance in the athletic training of dressage horses.

\section{Mobility of the equine spine}

The first modern work on equine gait dates from the late 18th century (Goiffon and Vincent 1779), and, after the breakthrough that was accomplished by Muybridge and Marey more than a century later, many studies have focused on equine locomotion in various aspects. However, studies on equine back movement have been extremely rare until very recently. This is due to the extreme difficulties that are encountered in visualising back movement, together with the relatively small movements of the equine spine, necessitating a high accuracy of the measuring method.

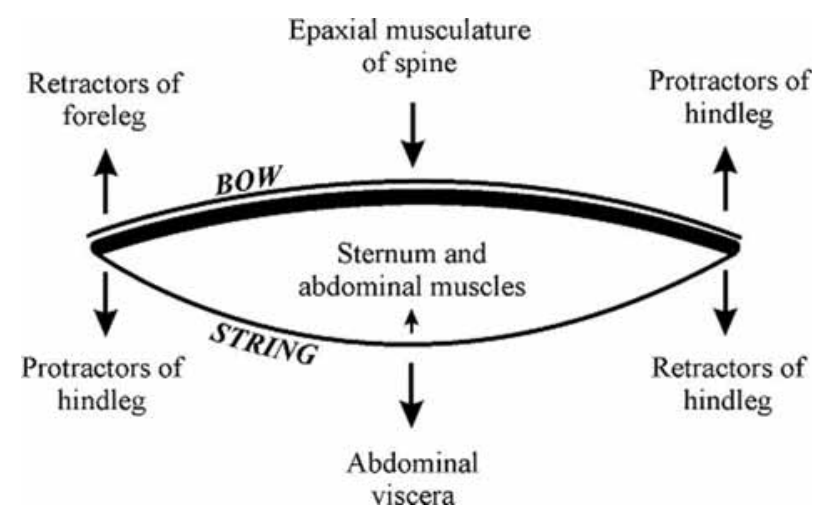

Fig 4 Factors that determine the motion of the back according to the "bow and string" concept.

Faktoren, die die Bewegung des Rückens entsprechend dem Konzept von "Bogen und Sehne" beeinflussen.



(a)

Flexion

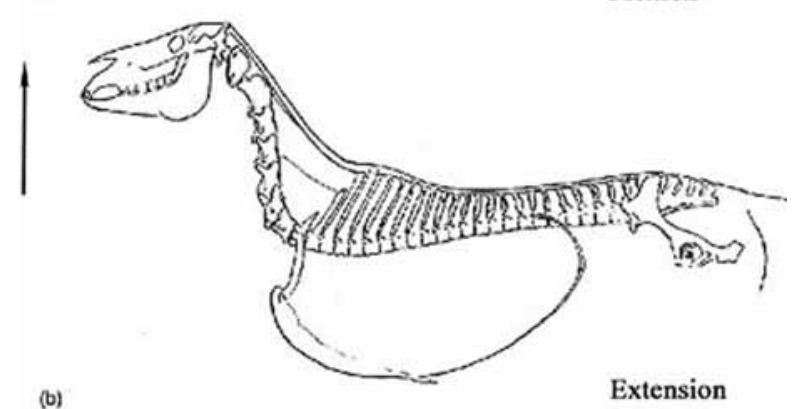

(b)

Extension

Fig 5 The effect of lowering (a) and raising (b) of the head on flexion and extension of the back. (Modified from: Denoix J. M. and Pailloux J. P. (2001): Physical Therapy and Massage for the Horse. 2nd ed. London, Manson Publishing.)

Die Auswirkung des Senkens (a) und Hebens (b) des Kopfes auf die Bewegung und Streckung des Rückens. (Modifiziert aus: Denoix J. M. and Pailloux J. P. (2001): Physical Therapy and Massage for the Horse. 2nd ed. London, Manson Publishing.) 
The basic movements of the equine spine are ventro- and dorsiflexion (or extension and flexion in the sagittal plane), lateroflexion or lateral bending, and axial rotation (Fig. 6a-c). These movements can be translated at the level of the individual vertebra into 3 rotations in an orthogonal coordinate system: one around the $X$-axis (flexion-extension), one around the Z-axis (lateroflexion), and one around the Y-axis (axial rotation) (Fig. 7).

In the early 80s the biomechanical research group of Doug Leach in Saskatoon published some in vitro work on movement patterns of the equine spine (Townsend et al. 1983, Townsend and Leach 1984). They found that the lumbar part of the spinal column was very rigid, especially with respect to lateroflexion, with increasing mobility in cranial direction. The same applied to axial rotation. It should be emphasised, however, that, although this work is of great value as it gives insight in the potential for movement of various parts of the equine spine, it does not represent reality, as there was obviously no influence of any of the active structures.

Recent work from the groups working at Alfort, in Vienna and in Utrecht has shed more light on the kinematics of the equi-

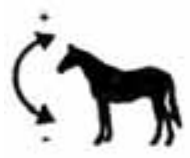

a

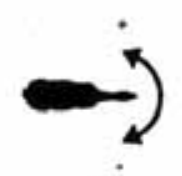

b

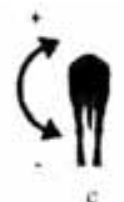

c
Fig 6 The three basic movements of the equine back: flexion/extension (a), lateroflexion or lateral bending (b), and axial rotation (c).

Die drei Grundbewegungen des Rückens: Beugung/Streckung (a), seitliche Beugung (b) und Achsenrotation (c).

ne back. The first approaches were non-invasive (Licka and Peham 1998, Pourcelot et al. 1998, Audigié et al. 1999). However, the complex and coupled movements of the vertebrae can never be adequately studied using surface markers. For instance, when a horse bends to the left or the right, the spine and hence the individual vertebrae will not only lateroflex, but also be subjected to axial rotation. This complex movement is not deducible from the change in position of a



Fig 7 The basic movements of the back depicted as rotations of an individual vertebra around the three axes of an orthogonal coordinate system.

Die Grundbewegungen des Rückens dargestellt durch die Rotation eines einzelnen Wirbels innerhalb der 3 Achsen eines orthogonalen Koordinatsystems. skin marker. In the Utrecht Equine Biomechanics Lab a large invasive experiment was carried out in which horses were first measured using skin markers and then, after placing Steinmann pins in the spinous processes of a number of vertebrae, using markers that were directly connected to the underlying bone. Data were acquired at walk (Faber et al. 2000), trot (Faber et al. 2001a) and canter (Faber et al. 2001b). Based on this data it was possible to develop a method by which real spinal kinematics can be predicted as good as possible from kinematic data obtained using skin markers (Faber et al. 2001c). The technique appeared to be highly reproducible, also when used in different lab settings (Faber et al. 2002).

Spinal motion is by far less at trot than in the other two gaits. At the walk, the range of motion for flexion-extension is fairly constant for vertebrae caudal to Th10 (approximately $7^{\circ}$ ), lateral bending is most outspoken in the cranial thoracic vertebrae and in the pelvic segments (values up to $5.6^{\circ}$ ), but less in the lumbar region between Th 17 and L5 $\left(<4^{\circ}\right)$. Axial rotation increases gradually from $4^{\circ}$ at Th6 to $13^{\circ}$ at the tuber coxae. At the trot the range for flexion-extension for all vertebrae does not pass 2.8-4.9 , lateral bending is even less $\left(1.9-3.6^{\circ}\right)$. Axial rotation at this gait is in the order of $3^{\circ}$. At the canter flexion-extension movement is substantially larger (maximal range $15.8 \pm 1.3^{\circ}$ ). Lateral bending is maximally $5.2 \pm 0.7^{\circ}$ and axial rotation $7.8 \pm 1.2^{\circ}$.

It should be noted that the shape of the curves partly depends on the gait. Flexion-extension movement has a double sinusoidal motion pattern at the walk and trot, but a single sinusoidal pattern at the canter. Lateroflexion has the form of a single peak and trough at all gaits, as has axial rotation. This has to do with the symmetry of the gait and the effect of hind limb placement on spinal kinematics. Typical examples of spinal motion patterns are given in figure 8 .

Variability within the same horse is limited for flexion-extension and axial rotation (6-8\%), but considerably more for lateroflexion (8-18\%). The variability between horses is larger, as could be expected, and the same applies here: lateroflexion may vary as much as $16-25 \%$ between individual horses, which is considerably more than the variation in the rotation around the other two axes (10-16\%) (Fig. 9).

\section{Conclusion}

It can be concluded that the equine back is a very complex structure that takes a central position in the entire equine musculoskeletal system and hence can be decisive for performance. A good knowledge of how the back works is therefore essential. The close interrelationship between the limbs and the back (and neck) is often underestimated. In a recent survey a group of orthopaedic patients and a control group of animals presented for a prepurchase exam were subjected to a full lameness examination as well as a full back examination, irrespective of their eventual complaints. In that study it appeared that the prevalence of lameness in horses with a diagnosed back problem was much higher than in horses without such a problem (Landman et al. 2004). The biomechanical concept of the action of the back is crucial too for a good understanding of various riding techniques in dressage horses and how certain training methods could affect the musculoskeletal system. It should be emphasised, however, that this matter is extremely complex, as there are many factors that may influence perfor- 
mance. Of these, use of the horse, the quality of the rider and the tack are among the most important. It can be anticipated
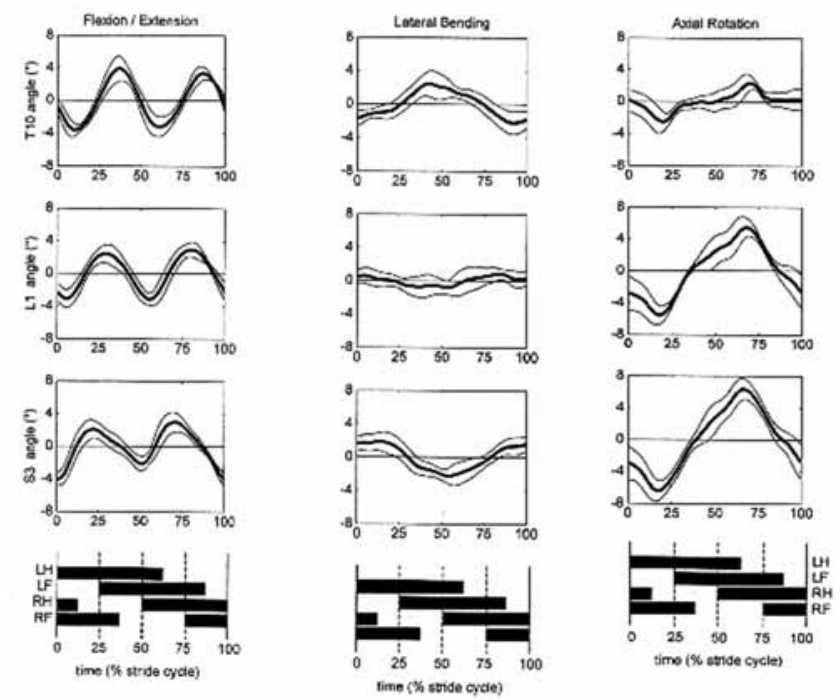

Fig 8 Mean motion patterns of 3 vertebrae (Th10, L1 and S3) of 5 horses walking on a treadmill at a speed of $1.6 \mathrm{~m} / \mathrm{s}$. The stride cycle is represented by the bars below (LH: left hind; $\mathrm{RH}$ : right hind; LF: left fore; RF: right fore). The bar is closed when the limb is in contact with the ground (stance phase). A: flexion/extension; B: lateral bending; C: axial rotation.

Durchschnittliche Bewegungsmuster von 3 Wirbeln (Th10, L1 und S3) bei 5 Pferden, die auf einem Laufband bei $1.6 \mathrm{~m} / \mathrm{s}$ Schritt gingen. Der Schrittzyklus wird durch eine Säule dargestellt (LH: links hinten, RH: rechts hinten, LF: links vorne, RF: rechts vorne). Die Säule ist voll dargestellt wenn die Gliedmaße mit der Lauffläche Kontakt hat. A: Beugung/Streckung; B: seitliche Beugung; C: Achsenrotation.
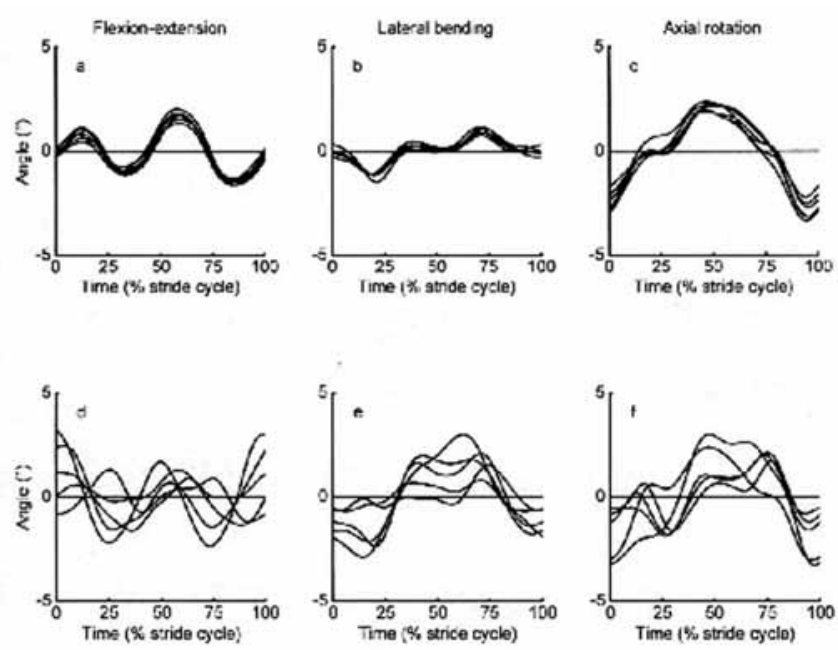

Fig 9 Intra-individual and inter-individual variation with respect to the three basic movements.

Intra-individuelle und inter-individuelle Schwankungen für die drei Grundbewegungen derWirbelsäule.

that, notwithstanding the limitations all kinematic gait analysis systems suffer (van Weeren 2002), computerised analysis of spinal kinematics will become more popular as an aid in diagnosis and to monitor recovery and/or the success of chosen therapies.

\section{Literature}

Audigié F., Pourcelot P., Degeurce C., Denoix J. M. and Geiger D. (1999): Kinematics of the equine back: flexion-extension movements in sound trotting horses. Equine vet. J. Suppl. 30, 210-213

Bergmann C. (1847): Über die Verhältnisse der Wärme-Ökonomie der Thiere zu ihrer Grösse. Göttinger Studien, Abt. 1.

Denoix J. M. (1999): Ultrasonographic evaluation of back lesions. Vet. Clin. North Am. Equine Pract. 15, 131-159

Faber M. J., Schamhardt, H. C., van Weeren P.R., Johnston C., Roepstorff L. and Barneveld A. (2000): Basic three-dimensional kinematics of the vertebral column of horses walking on a treadmill. Am. J. Vet. Res. 61, 399-406

Faber M. J., Johnston C., Schamhardt H. C., van Weeren P. R., Roepstoff L. and Barneveld A. (2001a): Basic three-dimensional kinematics of the vertebral column of horses trotting on a treadmill. Am. J. Vet. Res. 62, 757-764

Faber M. J., Johnston C., Schamhardt H. C., van Weeren P.R., Roepstoff $L$. and Barneveld A. (2001 b): Three-dimensional kinematics of the equine spine during canter. Equine vet. J. Suppl. 33, 145-149

Faber M. J., Schamhardt H. C., van Weeren P. R. and Barneveld A. (2001c): Methodology and validity of assessing kinematics of the thoracolumbar vertebral column in horses based on skin-fixated markers. Am. J. Vet. Res. 62, 301-306

Faber M. J., Johnston C., van Weeren P. R. and Barneveld A. (2002): Repeatability of back kinematics in horses during treadmill locomotion. Equine vet. J. 34, 235-241

Faber M. J., van Weeren P. R. Schepers M. and Barneveld A. (2003): Long-term follow-up of manipulative treatment in a horse with back problems. J. Vet. Med. A 55, 241-245

Goiffon and Vincent (1779): Mémoire Artificiele des Principes relatifs à la Fidelle Répresentation des Animaux Tant en Peinture qu'en Sculpture. I. Partie concernant le cheval. Alfort: Ecole Royale Vétérinaire.

Landman M. A. A. M., de Blaauw J. A., van Weeren P. R. and Hofland L. J. (2004): Lameness prevalence in horses with back problems compared to a control population: a field study. Vet. Rec., accepted for publication.

Licka T. and Peham C. (1998): An objective method for evaluating the flexibility of the back of standing horses. Equine vet. J. 30, $412-415$

Lupton J. I. (1876): Mayhew's Illustrated Horse Management. London: $\mathrm{Wm} \mathrm{H}$. Allen \& Co.

Pourcelot P., Audigié F., Degueurce C., Denoix J. M. and Geiger D. (1998): Kinematics of the equine back: a method to study the thoracolumber flexion-extension movements at the trot. Vet. Res. 29, 519-525

Slijper E. J. (1946): Comparative biologic-anatomical investigations on the vertebral column and spinal musculature of mammals. Proc. K. Ned. Acad. Wetensch. 42, 1-128

Townsend H. G., Leach D. and Fretz P.B. (1983): Kinematics of the equine thoracolumbar spine. Equine vet. J. 15, 117-122

Townsend H. G. and Leach D. (1984): Relationship between intervertebral joint morphology and mobility in the equine thoracolumbar spine. Equine vet. J. 16, 461-465

Van Weeren P. R. (2002): The clinical applicability of automated gait analysis systems. Equine vet. J. 34, 218-219

Zschokke E. (1892): Untersuchungen über das Verhältnis der Knochenbildung zur Statik und Mechanik des Vertebraten-skelettes. Thesis, Zürich

P. René van Weeren DVM PhD Dipl ECVS

Department of Equine Sciences

Faculty of Veterinary Medicine

Utrecht University

Yalelaan 12

3584 CM Utrecht

The Netherlands

r.vanweeren@vet.uu.nl 